\title{
Examining of Conservatory Students' Mental Well-Being Levels Aspects of Various Variables
}

\section{Sibel Celik ${ }^{1 \rtimes(D)}$ Alper Semih Sari ${ }^{2}$}

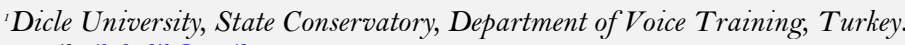
Email:sibelcelik@mail.ru

${ }^{\circ}$ Ministry of National Education, Turkey.

Email:alpersemihsari@gmail.com

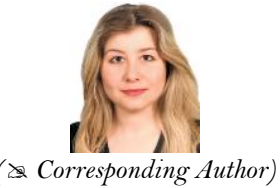

( Corresponding Author)

\section{Abstract}

The basic aim of this study is to specify mental well-being levels and investigate some various conservatory students. Conservatory students studying at Dicle University and Gaziantep University State Conservatory in the 2020-2021 academic year participated in the research. Purposeful sampling was used in this study, which was carried out with a quantitative research model. Data collection has been made via Warwick-Edinburgh Mental Well-Being Scale and socio-demographic information form designed by the researchers. In the data analysis, the MannWhitney U test was used for pairwise group comparisons and the Kruskal-Wallis $\mathrm{H}$ test was used for comparisons of more than two groups. While a significant difference came up among the mental well-being levels of conservatory students and the variables of age, the department they study, academic achievement levels, family income status, and number of siblings, no meaningful difference came up among the variables of gender, music style they listened to, and where they live. It is thought that this research is considerable in terms of contributing to the development of the methods applied in the education of conservatory students and to the studies applied in this field.

Keywords: Art education, Conservatory education, Conservatory students, Mental well-being, Music education, Psychological well-being.

Citation | Sibel Celik; Alper Semih Sari (2022). Examining of Conservatory Students' Mental Well-Being Levels Aspects of Various Variables. Asian Journal of Education and Training, 8(1): 17. History:

Received: 23 November 2021

Revised: 3 January 2022

Accepted: 14 January 2022

Published: 21 January 2022

Licensed: This work is licensed under a Creative Commons Attribution 3.0 License (oc)

Publisher: Asian Online Journal Publishing Group
Funding: This study received no specific financial support.

Authors' Contributions: Both authors contributed to the conception and design of the study.

Competing Interests: The authors declare that they have no conflict of interests.

Transparency: The authors confirm that the manuscript is an honest, accurate, and transparent account of the study was reported; that no vital features of the study have been omitted; and that any discrepancies from the features of the study have been omitted
study as planned have been explained. study as planned have been explained.
Ethical: This study follows all ethical practices during writing.

\section{Contents}

1. Introduction 2

2. Method

3. Findings

4. Discussion

5. Conclusion

References. 


\section{Contribution of this paper to the literature}

This study contributes to existing literature by examining mental well-being levels of conservatory students by the various variables. So, this issue is thought to be better understood and it is estimated to be useful for future studies.

\section{Introduction}

In human life, positive mental health notion and contribution of all outlooks of human life have risen in international scope. Positive mental health is the basis of well-being and effective functioning, both for the "individual and society" declared by World Health Organisation (2004) and defined this as a situation that permits individuals to realize their abilities and to handle them. In this context, all the positive traits that make up individuals, united thoughts and behaviors are the psychological state (Tekkurșun, Naml, Hazar, Türkeli, \& Cicioğlu, 2018). Mental well-being, which includes the psychological and subjective well-being of individuals, is the state of mental well-being conceptualized by positive psychology, which Freud summarized as being able to cultivate and love. Mental well-being is not just a concept that describes the absence of any psychological disorder. It is a concept that emphasizes having a chaste and meaningful life, frequent positive feelings, less negative emotions, being satisfied with life, and being functional (Diener, Pressman, Hunter, \& Delgadillo-Chase, 2017).

Positive mental health largely in both senses is used. As a notion, both in the academic literature and the term mental health have the same meaning with each other. Both affection (emotion) and involving psychological functioning complicated structure with two different perspectives. The hedonic perspective zooms on the nominative experiences of bliss and life satisfaction, moreover, the eudaemonic perspective is on psychological functioning and self- actualization. As a result, mental well-being is stated as an individual's positive perception of himself, being satisfied with himself even when he is aware of his limitations, developing safe and warm relationships with others, shaping the environment to meet his personal needs and wishes, acting autonomously and independently, having an aim and meaning in life, and being aware of his capacity and its efforts to develop this capacity (Keyes, Shmotkin, \& Ryff, 2002).

Nowadays, music has been used by medicine to remove pain and stress. Educators have used music to increase psychosocial and cognitive well-being rising in the classroom (Rickard \& McFerran, 2012). It has been shown that individuals' being busy with music increases the effect of well-being (Bieligmeyer, Helmert, Hautzinger, \& Vagedes, 2018; Lee, Krause, \& Davidson, 2017).

Conducted studies revealed that some demographic variables function of the mental well-being status. Such as gender, living place, economic status, age, those factors have emerged as the most substantial variables in order to evaluate in some situation. Ryff underlines that the level of mental well-being differs by gender. Moreover, it was concluded that men had considerably higher levels of mental well-being than women. Broady, Hall, and Lucas, and Gohm's research on gender revealed that women experience unpleasant feelings more intensely than men, and accordingly, their mental well-being levels are lower than men. Again, in line with these studies, it has been detected that mental well- being is more important for women, and men are less inclined to be mentally well (Ozen \& Gülaçti, 2010). In another study, while they determined that men are ahead of women in terms of mental well-being, they came up with that woman are in a better state than men (Haring, Stock, \& Okun, 1984).

The level of mental well-being increases in direct proportion with age, which is among the concepts that affect the progress of mental well-being, and accordingly, the level of creating positive relationships for the person (Bakır, 2017). On the other hand, it is a largely admitted assumption that there is a positive correlation between socio-economic status and mental well-being. Many studies have been conducted in this direction and are proof (Furnham \& Cheng, 1997). Studies show that people with high mental well-being; concluded that their physical and psychological health is very good, and their quality of life is strong (Keyes, 2002; Keyes, Dhingra, \& Simoes, 2010). Essentially, it has been defined that individual with a superior level of mental well-being have strong creativity and immune systems, have very good relationships with other individuals, and are very productive at work (Lyubomirsky, King, \& Diener, 2005). When the relevant literature was examined, it was seen that there was no study examining the metal well-being levels of conservatory students. In this context, it can be said that the research constitutes a distinctive and original. It is thought that the research is important in terms of contributing to the development of the methods applied in the education of conservatory students and to the studies to be done in this field.

The outcomes of this study disclose that mental well-being is an important element at the environmental, social and personal level (Keldal, 2015). On this axis, study has looked for answers those questions:

1) What level is the mental well-being of conservatory students?

2) Are there significant differences in mental well-being levels of conservatory students equated to gender, age, university, department, family income, academic level, number of siblings, type of music listened to?

\section{Method}

Quantitative research model has been used in this study. Quantitative research is research that can be observed, measured and expressed numerically by concretizing facts and events (Creswell, 2013). The goal of quantitative research is to measure the behavior of individuals objectively through similar tools such as tests and questionnaires and to explain them with numerical data (Bergman, 2009). Dicle University State Conservatory and Gaziantep University Turkish Music State Conservatory studying in between 2020-2021; Turkish music, Voice Education, and Turkish folk dances department consisted of 1st, 2nd, 3rd and 4th grade students. In the study, purposive sampling technique was used. Purposeful sampling is the selection of information-rich situations in the context of a purpose of the study to conduct in- depth research. Criterion sampling is portrayed as the study of all situations that meet a set of predetermined criteria (Patton, 2002). 


\subsection{Data Collection Tools}

Personal Information Form: It was designed by the researcher which included gender, age, university, department, class, level of academic achievement, family income, number of siblings, the type of music listened to, and the place where they lived and gathered.

Warwick-Edinburgh Mental Well-Being Scale Turkish Version: Tennant et al. (2007) adapted into Turkish by Keldal (2015). The scale consists of 14 items in a 5-point Likert type. The total internal consistency coefficient of the one-dimensional scale is 0.89 . The lowest 14 points can be acquired from the scale, and the highest 70 points. Scoring of the scale is " $1=$ strongly disagree, $2=$ disagree, $3=$ somewhat agree, $4=$ agree, $5=$ strongly agree". All items of the scale are positive. High scores from the scale indicate high mental (psychological) well- being. A high score on the scale indicates high well-being. The adaptation Cronbach Alpha internal consistency reliability coefficient of the scale was determined as 0.92 . When the exploratory factor analyses of the scale are examined, it is observed that the sample fit coefficient is 0.85 and the scale explains $51 \%$ of the total variance (Keldal, 2015).

\subsection{Data Collection Procedure}

Research data, in the 2020-202 1 academic year, Dicle University State Conservatory and Gaziantep University Turkish Music State Conservatory Basic Sciences, Voice Education and Turkish Folk Dance Departments whole grades conservatory students via an online questionnaire. 258 students participated in the study, and a volunteer consent form was used while applying the scale.

\subsection{Analysis}

This statistical analysis has been carried out via the SPSS 23 program. Whether the data provide the prerequisites of parametric tests was determined by normality analysis. Before making comparisons, it was checked whether the scales were normally spread. One of the indicators used for the normality analysis was the dispersion of the data in the kurtosis and skewness values. Data with kurtosis and skewness values between -2.0 and +2.0 are considered to have normal distribution (George \& Mallery, 2010). WarwickEdinburgh Mental Well- Being Scale did not fulfil the normality assumption (Kolmogorov-Smirnov $=0.000$ $\mathrm{p}<0.05)$. Since it was determined that it did not fit the normal distribution, non-parametric test techniques were used in the comparisons. In the analysis of the data, Mann-Whitney $U$ test was used for pairwise group comparisons and Kruskal-Wallis H test was used for more than two group comparisons. On the other hand, Cronbach's alpha coefficient was determined as. 91 in this study. In order to be accepted in the study as reliable, it must value above 0.7 (Pallant, 2010). Therefore, this study is reliable.

Table 1. Distribution of conservatory students by socio-demographic information.

\begin{tabular}{|c|c|c|c|}
\hline Variable & Group & $f$ & $\%$ \\
\hline \multirow{2}{*}{ Gender } & Female & 141 & 54.7 \\
\hline & Male & 117 & 45.3 \\
\hline \multirow{3}{*}{ Age } & $18-24$ & 140 & 54.3 \\
\hline & $24-27$ & 59 & 22.9 \\
\hline & $27+$ & 59 & 22.9 \\
\hline \multirow{2}{*}{ University } & Dicle & 84 & 43.1 \\
\hline & Gaziantep & 111 & 56.9 \\
\hline \multirow{3}{*}{ Department } & Voice training & 99 & 38.4 \\
\hline & Basic sciences & 107 & 41.5 \\
\hline & Turkish folk dances & 52 & 20.2 \\
\hline \multirow{3}{*}{ Academic achievement level } & Low & 53 & 20.5 \\
\hline & Middle & 168 & 65.1 \\
\hline & High & 37 & 14.3 \\
\hline \multirow{8}{*}{ Preferred to music style } & Classical & 116 & 45.0 \\
\hline & Turkish folk & 14 & 5.4 \\
\hline & Turkish art & 16 & 6.2 \\
\hline & Popular & 8 & 3.1 \\
\hline & Jazz/blues & 33 & 12.8 \\
\hline & Arabesque & 8 & 3.1 \\
\hline & Rock & 15 & 5.8 \\
\hline & Others & 48 & 18.6 \\
\hline \multirow{4}{*}{ Residence of place } & Village & 120 & 46.5 \\
\hline & District & 35 & 13.6 \\
\hline & Province & 7 & 2.7 \\
\hline & Metropol & 96 & 37.2 \\
\hline \multirow{3}{*}{ Income level } & Low & 167 & 64.7 \\
\hline & Middle & 64 & 24.8 \\
\hline & High & 27 & 10.5 \\
\hline \multirow{5}{*}{ Sibling Information } & 1 & 43 & 16.7 \\
\hline & 2 & 66 & 25.6 \\
\hline & 3 & 48 & 18.6 \\
\hline & 3 and over & 98 & 38.0 \\
\hline & none & 3 & 1.2 \\
\hline \multicolumn{2}{|l|}{ Total } & 258 & 100 \\
\hline
\end{tabular}

\section{Findings}

In this section, the findings obtained by subjecting the data to statistical processes in line with the 
answers given by the respondents are contained.

As seen in Table 1, 54.7\% of the conservatory students attending in the study were female, $45.3 \%$ were male. $54.3 \%$ were between the ages of 18 and $24,22.9 \%$ were between the ages of $24-27$, and $22.9 \%$ were over the age of 27. The universities they study at were $43.1 \%$ at Dicle University, $56.9 \%$ at Gaziantep University. The departments are $38.4 \%$ Voice education, 4 1.5\% Basic sciences and 20.2\% Turkish folk dances. 20.5\% of them have low academic achievement, $65.1 \%$ are medium and $14.3 \%$ are high.

\begin{tabular}{l|c|c|c|l|c|c}
\multicolumn{7}{c}{ Table 2. The result of the Mann-Whitney U test showing mental well-being levels by gender. } \\
\cline { 1 - 5 } Gender & $\mathbf{n}$ & Mean Rank & Sum of Ranks & $\mathbf{U}$ & $\mathbf{z}$ & $\mathbf{p}$ \\
\hline Female & 141 & 126.17 & 17789.50 & 7778.500 & -0.788 & 0.431 \\
\hline Male & 117 & 133.52 & 15621.50 & & & \\
\hline
\end{tabular}

Considering the Table 2 , there was no meaningful difference $(z=-0.788 ; p>0.05)$ according to the results of the Mann-Whitney U test, which was conducted to determine whether the mental well-being levels of the conservatory students attending in the study differed significantly by the gender. In the light of the findings, the mental wellbeing levels of conservatory students did not differ by their gender.

Table 3. The result of the Kruskal-Wallis H test showing mental well-being levels by age.

\begin{tabular}{|c|c|c|c|c|c|c|}
\hline \multirow[t]{2}{*}{ Age } & \multicolumn{2}{|c|}{ Descriptive Statistic } & \multicolumn{3}{|c|}{ Kruskal-Wallis $\mathbf{H}$} & \multirow[t]{2}{*}{ Mann-Whitney L } \\
\hline & $\mathbf{n}$ & Mean Rank & $\chi^{2}$ & df & $\mathbf{p}$ & \\
\hline $1-18-23$ & 140 & 124.53 & \multirow{3}{*}{6.029} & \multirow{3}{*}{2} & \multirow{3}{*}{0.049} & \multirow{3}{*}{3 with 1,2} \\
\hline 2- $24-27$ age & 59 & 120.57 & & & & \\
\hline 3-28 age and over & 59 & 150.23 & & & & \\
\hline
\end{tabular}

In the Table 3, there was a significant difference $(\chi 2=6.029 ; \mathrm{p}<0.05)$ by the Kruskal-Wallis $\mathrm{H}$ test, which was performed to specify whether the mental well-being levels of the conservatory students attending in the study demonstrated a significant difference by the age. Post-hoc Mann-Whitney $\mathrm{U}$ test was applied to determine the age ranges of the difference, and it was determined that there was a difference between the 18-23 age range and 28 and over, 24-27 age range and 28 and over students. According to the findings, the mental well-being levels of conservatory students aged 28 and over (Mean Rank 28 age and over=150.23), age ranges 18-23 (Mean Rank $18-23$ ${ }_{\mathrm{age}}=124.53$ ) and 24-27 (Mean Rank $\mathrm{R}_{2-27 \mathrm{age}}=120.57$ ) is higher than that of conservatory students.

\begin{tabular}{|c|c|c|c|c|c|c|}
\hline \multirow[t]{2}{*}{ Department } & \multicolumn{2}{|c|}{ Descriptive Statistic } & \multicolumn{3}{|c|}{ Kruskal-Wallis $\mathrm{H}$} & \multirow[t]{2}{*}{ Mann-Whitney U } \\
\hline & $\mathbf{n}$ & Mean Rank & $\chi^{2}$ & df & p & \\
\hline 1-Voice Training & 99 & 114.92 & \multirow{3}{*}{6.555} & \multirow{3}{*}{2} & \multirow{3}{*}{0.038} & \multirow{3}{*}{1 with 2,3} \\
\hline 2- Basic Sciences & 107 & 135.93 & & & & \\
\hline 3-Turkish Folk Dances & 52 & 144.02 & & & & \\
\hline
\end{tabular}

When Table 4 is examined, according to the results of the Kruskal-Wallis $\mathrm{H}$ test, which was conducted to determine whether the mental well-being levels of the conservatory students participating in the study demonstrated a significant difference according to the department they studied, there was a significant difference $\left(\chi_{2}=6.555 ; \mathrm{p}<0.05\right)$. Post-hoc Mann-Whitney U test was applied to determine the age ranges of the difference, and it was determined that there was a differentiation between the conservatory students studying at the Voice Education department and the conservatory students studying at the Basic Sciences and Turkish Folk Dance departments. According to the findings, the mental well-being levels of the students studying at Turkish Folk Dances (Mean Rank $k_{\text {Turkish folk dances }}=144.02$ ) and Basic Sciences (Mean Rank $k_{\text {Basic sciences }}=135.93$ ) departments are higher than the conservatory students studying at Voice Education (Mean Rank $k_{\text {Voice Training }}=114.92$ ) departments.

Table 5. The result of Kruskal-Wallis H test showing the mental well- being levels according to academic achievement levels.

\begin{tabular}{l|c|c|c|c|c|c}
\hline \multirow{2}{*}{ Academic achievement level } & \multicolumn{2}{|c|}{ Descriptive Statistic } & \multicolumn{2}{|c|}{ Kruskal-Wallis H } & \multicolumn{2}{l}{ Mann-Whitney U } \\
\cline { 2 - 5 } & $\mathbf{n}$ & Mean Rank & $\boldsymbol{\chi}^{2}$ & $\mathbf{d f}$ & $\mathbf{p}$ & \\
\hline 1- Low & 53 & 93.85 & & & & \multirow{2}{*}{1 with 2,3} \\
\hline 2- Middle & 168 & 130.82 & 25.695 & 2 & \multirow{2}{*}{0.000} & 2 with 3 \\
\hline 3- High & 37 & 174.58 & & & & \\
\hline
\end{tabular}

In the Table 5 , there was a significant difference $\left(\chi^{2}=25.695 ; \mathrm{p}<0.05\right)$ in the results of the Kruskal- Wallis $\mathrm{H}$ test, which was conducted to determine whether the mental well-being levels of the conservatory students attending in the study showed a significant difference according to their academic achievement levels. Post-hoc Mann-Whitney $\mathrm{U}$ test was applied to determine between which academic achievement levels the difference was, and it was determined that there was a differentiation between conservatory students with low to medium to high, medium to high academic achievement levels. According to the findings, the academic success of the conservatory students with medium (Mean ${ }_{\text {Medium }}=130.82$ ) and high (Meanı ${ }_{\text {High }}=174.58$ ) conservatory students equated to the conservatory students with low (Mean RankLow $=93.85$ ) academic success of the conservatory students with high (Mean Rank $1_{\text {High }}=174.58$ ) academic success Mental well-being levels are higher than conservatory students who

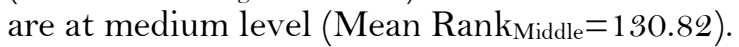


Table 6. The result of Kruskal-Wallis H test showing mental well- being levels by the preferred to music style.

\begin{tabular}{|c|c|c|c|c|c|}
\hline \multirow[t]{2}{*}{ Preferred Music Style } & \multicolumn{2}{|c|}{ Descriptive Statistic } & \multicolumn{3}{|c|}{ Kruskal-Wallis H } \\
\hline & $\mathbf{n}$ & Mean Rank & $\chi^{2}$ & df & $\mathbf{p}$ \\
\hline 1- Turkish folk & 116 & 134.72 & \multirow{8}{*}{7.015} & \multirow{8}{*}{7} & \multirow{8}{*}{0.427} \\
\hline 2- Turkish art & 48 & 127.63 & & & \\
\hline 3- Classical & 14 & 160.25 & & & \\
\hline 4- Rock & 8 & 137.88 & & & \\
\hline 5- Popular & 15 & 106.17 & & & \\
\hline 6- Jazz/blues & 8 & 104.69 & & & \\
\hline 7-Arabesque & 16 & 133.63 & & & \\
\hline 8-Others (Electronic, R\&B, rap) & 33 & 113.44 & & & \\
\hline
\end{tabular}

In the Table 6, according to the results of the Kruskal-Wallis $\mathrm{H}$ test, which was conducted to determine whether the mental well-being levels of the conservatory students participating in the study differed significantly by the music style they listened to, there was no significant difference $\left(\chi_{2}^{2}=7.015 ; \mathrm{p}>0.05\right)$. According to the findings, the mental well-being levels of conservatory students do not differ by the music style they listen to.

Table 7. Kruskal-Wallis H test showing mental well- being levels by the variable where they lived.

\begin{tabular}{l|c|c|c|c|c}
\hline \multirow{2}{*}{ Living place } & \multicolumn{2}{|c|}{ Descriptive Statistic } & \multicolumn{3}{|c}{ Kruskal-Wallis H } \\
\cline { 2 - 4 } & $\mathbf{n}$ & Mean Rank & $\boldsymbol{\chi}^{\mathbf{2}}$ & $\mathbf{d f}$ & $\mathbf{2}$ \\
\hline 1-Vilage & 120 & 123.35 & \multirow{2}{*}{2.114} & \multirow{2}{*}{0.549} \\
\hline 2- Province & 35 & 126.73 & & \\
\hline 3- Village & 7 & 132.57 & & \\
\hline
\end{tabular}

In the Table 7 , there is no significant difference $(\chi 2=2.114 ; \mathrm{p}>0.05)$ according to the results of the KruskalWallis $\mathrm{H}$ test, which was conducted to determine whether the mental well- being levels of the conservatory students participating in the study differed significantly according to the variable of where they spent their lives. According to the findings, the mental well-being levels of conservatory students do not differ according to the variable of the place where they spend their lives.

Table 8. Kruskal-Wallis H test showing mental well- being according to family income level.

\begin{tabular}{l|c|c|c|c|c|c}
\hline \multirow{2}{*}{ Income level } & \multicolumn{2}{|c|}{ Descriptive Statistic } & \multicolumn{2}{c|}{ Kruskal-Wallis H } & \multirow{2}{*}{ Mann-Whitney U } \\
\cline { 2 - 6 } & $\mathbf{n}$ & Mean Rank & $\chi^{2}$ & $\mathbf{d f}$ & $\mathbf{p}$ & \\
\hline 1- Low & 167 & 120.41 & & & \multirow{2}{*}{2 with 3} \\
\hline 2- Middle & 64 & 139.57 & \multirow{2}{*}{8.725} & 2 & \multirow{2}{*}{0.013} & \\
\hline 3- High & 27 & 161.83 & & & & \\
\hline
\end{tabular}

Considering the Table 8, the Kruskal-Wallis H test was conducted to determine whether the mental well-being levels of the conservatory students participating in the research differ significantly according to their family income levels. By the table, participants' mental well-being level has differed significantly according to income level of their families $\left(\chi^{2}=8.725 ; \mathrm{p}<0.05\right)$. The post-hoc Mann- Whitney $\mathrm{U}$ test was applied to determine between which family income levels the difference was, and it was determined that there was a differentiation between conservatory students whose families had low- and high-income levels. According to the findings, the mental well-being levels of conservatory students with high family income (Mean Rank $_{\mathrm{High}}=161.83$ ) are higher than those of conservatory students with low family income (Mean Rank $\mathrm{Low}_{\text {Lo }}=120.41$ ).

\begin{tabular}{|c|c|c|c|c|c|c|}
\hline \multirow{2}{*}{$\begin{array}{l}\text { Sibling } \\
\text { information }\end{array}$} & \multicolumn{2}{|c|}{ Descriptive Statistic } & \multicolumn{3}{|c|}{ Kruskal-Wallis $\mathbf{H}$} & \multirow[t]{2}{*}{ Mann-Whitney U } \\
\hline & $\mathbf{n}$ & Mean Rank & $\chi^{2}$ & df & p & \\
\hline $1-1$ & 43 & 125.65 & \multirow{5}{*}{10.403} & \multirow{5}{*}{4} & \multirow{5}{*}{0.034} & \multirow{5}{*}{$\begin{array}{l}2 \text { with } 3 \\
3 \text { with } 4\end{array}$} \\
\hline $2-2$ & 66 & 138.17 & & & & \\
\hline $3-3$ & 48 & 99.99 & & & & \\
\hline 4- More than 3 & 98 & 139.82 & & & & \\
\hline 5- None & 3 & 129.00 & & & & \\
\hline
\end{tabular}

In the Table 9, the Kruskal-Wallis $\mathrm{H}$ test was used to determine whether the mental well-being levels of the conservatory students participating in the study differed significantly according to the number of siblings. Accordingly, it was observed that there was a significant difference $\left(\chi^{2}=10.403, p<0.05\right)$. Post-hoc Mann-Whitney $\mathrm{U}$ test was applied to determine between which number of siblings the difference was, and it was determined that there was a differentiation between 2 siblings and 3 siblings, and 3 siblings and more than 3 siblings. According to the findings, conservatory students with 2 siblings (Mean Rank ${ }_{2}=138.17$ ) had more than 3 siblings (Mean $\mathrm{Rank}_{3}=99.99$ ), conservatory students with 3 siblings (Mean Rank ${ }_{3}=99.99$ ) had more than 3 siblings (Mean Rank $\left._{\text {more than } s}=161.83\right)$. Mental well-being levels are higher than those who have.

\section{Discussion}

Music is such a gift that has beyond time, place and limit helps understanding the awareness of spiritual life. It brings comfort and calmness to people in negative situations such as loss and hopelessness (Magill, 2006). Hereby, music is the most effective a tool for all human beings. In this study, conservatory students' mental well-being levels was determined by the various variables. Basically, the main aim is to define and emerge existing current situation of their on mental well-being to some factors. This situation appears to be at a normal level. With the 
results of the study, it shows that it does not differ dramatically by the sex. Supporting this finding, another study carried out with university students, it is seen that gender does not affect the level of mental well-being (Avsaroğlu, 2017; Diener \& Diener, 1995; Diener \& Ryan, 2009; Gönener, Oztürk, \& Yllmaz, 2017; Kılınçoğlu, 2020). In particular studies, it has been emerged that men have higher mental well-being levels than women (Arslandoğan, Türkmen, Töre, Demir, \& Hazar, 2021). The high level of mental well-being of women may be related to them being more open to personal development and communication. It can also be explained by the fact that they express their feelings and thoughts more.

Based on the findings obtained by age, there is a statistically substantial difference in the mental well-being levels of the participants aged 27 and over, according to the 18-21 and 21-24 age groups. In another study, Sahin (2018) examined whether mindfulness influences life satisfaction and well-being levels in university students; determined that mental well- being showed a significant difference according to the age variable. Therefore, determined that the level of mental well-being increased with increasing age. Ryff (1989) stated that there is no direct relationship between the level of mental well-being and the age variable.

In the research, it has come up that the mental well-being levels by the department are higher than the other two departments of the Turkish Folk Dances Department - Voice Education and Basic Sciences Department. Since there is a department related to physical activity, it can be stated that the mental well-being of the students of this department is high. Indeed, the findings of some studies on this issue induce the results of our study. Physical activity appears to increase psychological well-being. The study carried out by Zengin and Razak (2016), was reported that individuals with high physical activity levels also have good mental well-being levels, and that they are healthier and happier. Namely, it can be concluded that individuals with high physical activity can have better quality and happier lives. As a result, it was determined in the study that individuals with high physical activity also had high mental well-being. In the pandemic period, it was determined that the difference between the mental wellbeing of negatively affected, unaffected and positively affected individuals was not statistically significant (Arslandoğan et al., 2021).

Another research findings reveal that the well-being of the students in the faculty of sports sciences, who are engaged in sports, is higher than the students of the department of music education, who are in a more intense music environment, and the students of the faculty of theology, who worship more. The research gives an idea about the fact that sports are more effective than music and worship in terms of well-being, but further research is needed to determine whether the well-being of individuals will be higher with sports, music or worship (Onuray, 2020).

When the perceived economic levels of the conservatory students included in our study were equated, it was determined that their mental well-being differed significantly. It also shows parallelism in studies conducted in our country (Cenkseven, 2004; Ilhan, 2009; Zümbül, 2019). On the other hand, there are also studies that do not comply with this judgment. In another study (Karabeyeser, 2013), it has been determined that it does not affect according to the economic level and there is no significant differentiation. Low-income levels of individuals lead to a decrease in mental well-being and affect physical health. Based on the general opinion in the studies carried out it can be stated that high income has affirmative effect on mental well-being.

When the mental well-being scores and perceived academic achievement levels of conservatory students were equated, it was determined that mental well-being scores differed significantly. It is seen that the participants with high academic success have high mental well- being levels. Therefore, it was determined that the higher the academic achievement level, the higher the mental well-being average score of the students (Tuzgöl-Dost, 2004). It can be expressed that mental well-being affects academic success, as self-esteem and being aware of the individual's capacity will bring about the desire to achieve success. In the study conducted by Gönener et al. (2017) to examine the effect of university students' mental well-being on their happiness levels, no significant difference was found between perceived academic success and mental well-being. It has been determined that the higher the academic achievement level, the higher the mean score of the students' mental well-being. Some results have paralleled with our research, it is seen that as the level of academic achievement increases, the mental well-being also increases.

\section{Conclusion}

This study gained the various specifically results, however it has some limitations. Mainly, it has been voluntarily participants at conservatories. This study included locations is Southeast Anatolian region. The gained data was studying at two conservatories of participants chiefly. Therefore, the subject should be examined by various variables at other conservatories, faculty of fine arts, music teachers or pre-service music teachers. On the other hand, current studies have not shown at all in literature by the conservatory students in term of mental wellbeing status. Consequently, research needs to be strongly supported. Deep research is needed in the effect of music towards mental well-being. On this axis, it should be investigated according to music styles as well, whether it effects or not by the mental well-being.

\section{References}

Arslandoğan, A., Türkmen, M., Töre, E., Demir, B., \& Hazar, S. (2021). The investigation of the relationship between physical activity level and mental well-being during The Covid-19. Sivas Cumhuriyet University Journal of Sport Sciences, 2(2), 67-75.

Avsaroğlu, Z. (2017). Investigation of the effect of the positive psychology study given in a period of the students on the mental good organization and personal good generation. Unpublished Master Thesis, Usküdar University, Institute of Social Sciences Istanbul.

Bakır, Y. (2017). The effect of sports on the level of mental well-being and positivity in adolescents WHO play sports regularly at secondary education level. Unpublished Master Thesis. Cumhuriyet University, Sivas.

Bergman, M. (2009). Peirce's philosophy of communication: The rhetorical underpinnings of the theory of signs. New York: Bloomsbury Publishing.

Bieligmeyer, S., Helmert, E., Hautzinger, M., \& Vagedes, J. (2018). Feeling the sound-short-term effect of a vibroacoustic music intervention on well-being and subjectively assessed warmth distribution in cancer patients-A randomized controlled trial. Complementary Therapies in Medicine, 40, 171-178.Available at: https://doi.org/10.1016/j.ctim.2018.03.002.

Cenkseven, F. (2004). Examining the predictors of subjective and psychological well-being of university students. Unpublished PhD Dissertation. Adana Cukurova University.

Creswell, J. W. (2013). Research design: Qualitative, quantitative, and mixed methods approaches (4th ed.). London: Sage Publications, Inc. 
Diener, E., \& Diener, M. (1995). Cross-cultural correlates of life satisfaction and self- esteem. Journal of Personality and Social Psychology, $68(4), 653-663$.

Diener, E., \& Ryan, K. (2009). Subjective well-being: A general overview. South African Journal of Psychology, 39(4), 391-406.Available at: https://doi.org/10.1177/008124630903900402.

Diener, E., Pressman, S. D., Hunter, J., \& Delgadillo-Chase, D. (2017). If, why, and when subjective well-being influences health, and future needed research. Applied Psychology: Health and Well-Being, 9(2), 133-167.

Furnham, A., \& Cheng, H. (1997). Personality and happiness. Psychological Reports, 80(3), 761-762.

George, D., \& Mallery, P. (2010). SPSS for windows step by step: A simple guide and reference 17.0 update (10th ed.). Boston: Pearson.

Gönener, A., Oztürk, A., \& Yllmaz, O. (2017). The effects of mental (Psychological) well being levels on happiness levels of Kocaeli University Faculty of Sports Science Students. Sportive Sight: Journal of Sports and Education, 4(1), 44-55.

Haring, M. J., Stock, W. A., \& Okun, M. A. (1984). A research synthesis of gender and social class as correlates of subjective well-being. Human Relations, 37(8), 645-657.Available at: https://doi.org/10.1177/001872678403700805.

Ilhan, T. (2009). The self-concordance model of university students: Life goals, basic need satisfaction, and subjective well-being. Unpublished PhD Dissertation. Gazi Universitesi, Ankara.

Karabeyeser, M. (2013). Psychological well - being of university students according to parental attitudes and stressful life events. Unpublished Master Thesis. Hacettepe University, Institute of Social Sciences, Ankara.

Keldal, G. (2015). Turkish version of the warwick-edinburgh mental well-being scale: A validity and reliability study. The Journal of Happiness \& Well-Being, 3(1), 103-115.

Keyes, C. L. (2002). The mental health continuum: From languishing to flourishing in life. Journal of Health and Social Behavior, 43(2), 207222.Available at: https://doi.org/10.2307/3090197.

Keyes, C. L., Dhingra, S. S., \& Simoes, E. J. (2010). Change in level of positive mental health as a predictor of future risk of mental illness. American Journal of Public Health, 100(12), 2366-2371.

Keyes, C. L. M., Shmotkin, D., \& Ryff, C. D. (2002). Optimizing well-being: The empirical encounter of two traditions. Journal of Personality and Social Psychology, 82(6), 1007-1022.Available at: https://doi.org/10.1037/0022-3514.82.6.1007.

Kılınçoğlu, B. (2020). The examination of mindfulness and mental well-being on university students. Unpublished Master Thesis. Baskent University Institute of Health Sciences, Ankara.

Lee, J., Krause, A. E., \& Davidson, J. W. (2017). The PERMA well-being model and music facilitation practice: Preliminary documentation for well-being through music provision in Australian schools. Research Studies in Music Education, 39(1), 73-89.

Lyubomirsky, S., King, L., \& Diener, E. (2005). The benefits of frequent positive affect: Does happiness lead to success? Psychological Bulletin, $131(6), 803-855$

Magill, L. (2006). Music therapy and spirituality and the challenges of end-stage illness. In D. Aldridge \& J. Fachner (Eds.), Music and altered states: Consciousness, transcendence, therapy and addictions (pp. 172-183). London: Jessica Kingsley.

Onuray, E. H. (2020). Comparison of the well-being of students of sports sciences, theology and music education. Manisa Celal Bayar University Journal of Social Sciences, 18(4), 297-310.

Ozen, Y., \& Gülaçti, F. (2010). Personal responsibility in the context of creating subjective and psychological well-being (A Social Psychological Assessment). Dicle University, The Journal of Institute of Social Sciences, 2(4), 46-58.

Pallant, J. (2010). SPSS survival manual: A step by step guide to data analysis using the SPSS program (4th ed.). New York: McGraw Hill.

Patton, M. Q. (2002). Qualitative research and evaluation methods Thousand Oaks, CA: Sage.

Rickard, N. S., \& McFerran, K. (2012). Lifelong engagement with music: Benefits for mental health and well-being. Hauppauge NY: Nova Science Publishers.

Ryff, C. D. (1989). Happiness is everything, or is it? Explorations on the meaning of psychological well-being. Journal of Personality and Social Psychology, 57(6), 1069-1081.

Sahin, A. (2018). The relationship between mindfulness and life satisfaction \& well-being among. Uskiudar University Journal of Social Sciences, $8,151-176$.

Tekkurşun, D., Namlı, S., Hazar, Z., Türkeli, A., \& Cicioğlu, İ. (2018). Investigation of individual and team athletes' decision making styles and the level of mental well-being. CBU Journal of Physical Education and Sports Sciences, 13(1), 176-191.

Tennant, R., Hiller, L., Fishwick, R., Platt, S., Joseph, S., Weich, S., . . Stewart-Brown, S. (2007). The Warwick-Edinburgh mental wellbeing scale (WEMWBS): Development and UK validation. Health and Quality of Life Outcomes, 5(1), 50-63.

Tuzgöl-Dost, M. (2004). Subjective well-being levels of university students. Unpublished PhD Dissertation, Hacettepe University Institute of Social Sciences, Department of Educational Sciences: Ankara.

World Health Organisation. (2004). Promoting mental health; Concepts emerging evidence and practice. Summary Report Geneva; World Health Organisation.

Zengin, A. A., \& Razak, Ö. A. (2016). Physical activity and preventive effect: Review. Journal of Health Science and Profession, 3(1), 66-72.

Zümbül, S. (2019). Mindfulness and forgiveness as predictors of psychological well-being levels of teacher candidates. Ege Journal of Education, 20(1), 20-36. 